\title{
Cartas para Murilo Miranda, o amigo com quem envelheço
}

\author{
[ Letters to Murilo Miranda, the friend with I grow old
}

\section{Mônica Gomes da Silva ${ }^{\mathrm{I}}$}

\section{Matildes Demétrio dos Santos ${ }^{2}$}

\begin{abstract}
RESUMO - No conjunto da correspondência de Mário de Andrade a Murilo Miranda, entre 1934 e I945, encontra-se um Mário muito distante da utopia vanguardista dos primeiros anos do Modernismo brasileiro. Nesse novo ambiente literário e intelectual, move-se o escritor, dominado pelo desencanto, que encontra em Murilo Miranda, um jovem estudante de Direito, o interlocutor ideal com quem costurou fatos de sua atividade artística fraturada à frente do serviço público, e depois empreendeu discussões sobre os princípios da "arte de ação pela arte", literatura e ética. - PALAVRAS-CHAVE • Correspondência literária; Mário de Andrade; Murilo Miranda.
\end{abstract}

\begin{abstract}
-ABSTRACT - In the set of Mário de Andrade's correspondence to Murilo Miranda, between I934 and I945, there is a Mário very different from the avantgarde utopia of the early years of the Brazilian Modernismo. In this new literary and political environment, the writer moves, dominated by disenchantment, who finds himself in Murilo Miranda, a young student of Law, the ideal interlocutor with whom he sewn facts of his fractured activity in front of the public service, and then, he overtook discussions on the principles of "art of action for art", literature and ethics. - KEYWORDS · Literary correspondence; Mário de Andrade; Murilo Miranda
\end{abstract}

Recebido em Io de setembro de 2020 Aprovado em 3 de setembro de $202 I$

SILVA, Mônica Gomes da; SANTOS, Matildes Demétrio dos. Cartas para Murilo Miranda, o amigo com quem envelheço. Revista do Instituto de Estudos Brasileiros, Brasil, n. 80, p. 88-Io3, dez. 202 I.

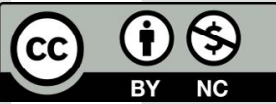

DOI: https://doi.org/Io.II606/issn.23I6-90IX.vIi8op88-I03

I Universidade Federal do Recôncavo da Bahia (UFRB, Amargosa, BA, Brasil).

2 Universidade Federal Fluminense (UFF, Niterói, RJ, Brasil). 
Uma coisa quero lhe dizer, Murilo. Está claro, eu tenho minhas dúvidas sobre tudo o que vocês poderão pensar sem mal, desta reviravolta brusca de minha vida e de eu ter aceitado um cargo de funcionário público. (ANDRADE, I98I, p. I8).

Dentro do vasto painel epistolar de Mário Raul de Moraes Andrade (I893-I945) destaca-se a correspondência com o advogado e jornalista Murilo Miranda (I9I2-I97I). Atualmente, é possível conhecer parte da correspondência dos escritores através da obra Mário de Andrade: cartas a Murilo Miranda (I934-I945), organizada por Yedda Braga Miranda (I98I), esposa de Murilo. Nessa edição, com notas de Raúl Antelo, é publicada a correspondência ativa de Mário de Andrade com o escritor carioca.

Conforme reportagem sobre o Acervo Mário de Andrade para a Folha de S. Paulo ("Murilo Miranda é quem escreveu mais", 22 de julho de I997), as cartas de Murilo Miranda possuem grande relevância no panorama da correspondência marioandradina: "Editor da Revista Acadêmica, ligada a intelectuais de esquerda, ele tomava Mário de Andrade como um guru, segundo a professora Telê Ancona Lopez, escrevendo quase que diariamente ao autor". Aquele que seria dos mais assíduos correspondentes de Mário cursava o segundo ano do curso de Direito na Faculdade do Rio de Janeiro, quando fundou o periódico que, de I933 a I948, teve uma função artística e cultural, de maneira independente e responsável, ao mesmo tempo cheio de ideias e reflexão contra o provincianismo conservador e a crença favorável às ideologias defendidas pelos adeptos dos regimes de força.

No entanto, o consenso moderador não foi a regra que predominou na história dessa extraordinária quantidade de cartas 3 , pois esse legado mostra traços excepcionais de contestação e divergência marcados pelo rigor mais suscetível. Mário sentia-se no dever de protestar contra um pedido que julgava inoportuno: "Você na sua última carta insiste em me pedir umas palavras sobre Romain Rolland.

3 Em levantamento realizado no Instituto de Estudos Brasileiros (IEB), há o registro de 334 documentos referentes à correspondência entre Mário de Andrade e Murilo Miranda. 
Ora decididamente não escreverei nada. [...]. Não praticarei uma hipocrisia que não tenho" (ANDRADE, I98I, p. 35). Na carta de II de novembro de I936, o remetente recusava o convite do editor da revista exatamente "naquilo que eles queriam falar, no Romain Rolland comunista” (ANDRADE, I98I, p. 35).

Para o Correio da Manhã, de 24 de abril de I944, Mário já havia escrito sobre "Romain Rolland, músico”, mas no epitexto privado da carta achava-se em condições de revelar que não julgava satisfatório redigir um documento publicitário que enaltecesse o intelectual favorável à imagem de "nova sociedade”, preconizada pela União Soviética. Lendo a nota de Raúl Antelo (ANDRADE, I98I, p. 35, nota I9), sabe-se que Romain Rolland foi saudado no número de setembro de I946 de Acadêmica com artigos amistosos, redigidos e assinados por Aníbal Mendonça, José Lins do Rego, Manuel Bandeira, Máximo Gorki, Stefan Zweig, entre outros. Semelhante boa vontade, tiveram Ugo Adami e Cândido Portinari, que aceitaram pintar retratos do pensador francês para a revista.

Em princípio, a duração de uma correspondência não ocorre sem a anuência cortês entre emissor e destinatário, mas muito se pode dizer que a crítica sincera, a vivacidade espiritual de Mário e, sobretudo, os autocomentários, confissões e elogios dirigidos ao interlocutor eram gestos de quem buscava com a sutilíssima precaução de homem "muito precavido, de-certo questão de idade" (ANDRADE, I98I, p. II), uma filiação intelectual e afetiva, um sucessor póstumo capaz de compreender as razões que levaram o escritor independente a assumir a chefia no Departamento de Cultura da cidade de São Paulo e depois, quando Mário, sentindo-se derrotado, perdeu o cargo e veio para o Rio de Janeiro, passando a conviver, quase que diariamente, com o amigo mais jovem.

No Brasil, as décadas de I930 e I940 são marcadas por radicalizações ideológicas e revoltas políticas num cenário de grande efervescência cultural, e essa conjuntura reúne alguns dos componentes explosivos que alimentam, estimulam e agridem tanto o modernista no exercício de funcionário público, quanto o jovem amigo, estudante de Direito e partidário de ideias revolucionárias.

Partindo dessas constatações acerca da importância das cartas de Mário de Andrade e Murilo Miranda, propomos apresentar a análise parcial dessa troca epistolar dividindo este artigo em mais duas partes. Assim, sabendo que "as cartas são textos híbridos e rebeldes a quaisquer identificações genéricas” (DIAZ, 20I6, p. II), na seção “O que buscamos nas cartas de escritores?”, a preocupação é abordar o texto epistolar na sua ambivalência, amarrado simultaneamente à efervescência da vida cotidiana e à história de um tempo histórico social e político. Na seção "O amigo com quem envelheço”, sobressai a voz de Mário de Andrade no diálogo com Murilo Miranda, manifestando aqui e ali alguma parcimoniosa desaprovação, porém sempre disposto a compartilhar suas angústias e seus questionamentos acerca da condição do artista no contexto ditatorial e bélico do estado getulista. Por fim, tendo por base de pesquisa as cartas de Mário de Andrade a Murilo Miranda, tecem-se algumas considerações sobre a trajetória cheia de embaraços e conflitos de um intelectual dionisíaco que, mesmo não sabendo conciliar atividade político-partidária e ideal artístico, volta-se para o seu destinatário e convida com sedutora provocação: "Venha ver companheiro, venha principalmente saber, que é já uma história de vários volumes" (ANDRADE, I98I, p. 40). 
Ideal e simbolicamente, Murilo Miranda era promovido a leitor e coparticipante de uma história de vida por vir...

\title{
O que buscamos nas cartas de escritores?
}

\author{
[...] é justamente na distância entre sonho e \\ realidade, entre projeto de vida e verdade de \\ existência, que buscaremos nossa matéria de \\ reflexão. (TODOROV, 20I4, p. 34).
}

Desde meados da década de I990, é possível acompanhar um crescente interesse pela carta, seja através da quantidade expressiva de estudos sobre o gênero epistolar, seja por meio da publicação do acervo particular de vários missivistas. A importância que o gênero passa a adquirir, do ponto de vista tanto acadêmico, quanto editorial, correlaciona-se, diretamente, ao avanço tecnológico que promoveu uma nova etapa para a correspondência: o eletronic mail. "De repente, não mais que de repente", essa espécie de substituto virtual se propaga e revoluciona a troca epistolar, instaurando novas formas de sociabilidade e de comunicação escrita.

Embora haja divergências no campo crítico se, de fato, o e-mail é o sucedâneo digital da carta ou se desapareceram a forma e a função da missiva, existe um consenso no sentido de que o advento do correio eletrônico gerou, em estudiosos e leitores em geral, sentimentos de perda e de urgência (GALVÃO, 2008, p. I5). O que se conquistou em imediatismo e praticidade para o envio da mensagem escrita acarretou, em contrapartida, a perda da "aura" de objeto particular, exclusivo e artesanal que constitui a missiva.

À aparente extinção desse mundo milenar ${ }^{4}$ contrapõe-se o movimento de resgate e valorização da carta, sublinhando, assim, num primeiro instante, a sua materialidade. Corpo textual que traz consigo as marcas do corpo físico em que "Visão, tato, olfato contribuem para substituir a presença do remetente" (HAROCHE-BOUZINAC, 20I6, p. 6I), não há paralelo, nas mensagens virtuais, intangíveis corpos escritos, dessa espécie de partilha física do eu, indo desde a escolha do papel, o preenchimento da página, os traços peculiares de cada caligrafia, até o envio de lembranças materiais e corporais do missivista: a carta é um "objeto investido de forte valor afetivo" (HAROCHE-BOUZINAC, 20I6, p. 64), chegando a surgir uma semiografia para descrever as relações de sentido entre carta e imagem (HAROCHE-BOUZINAC, 20I6, p. 62) como "Objetos únicos" (GALVÃO, 2008, p. I7). Quando resguardados dos reveses e das intempéries vividas por seus correspondentes, as cartas perduram e parecem ganhar da volatilidade da mensagem eletrônica, que, uma vez lida, estaria fadada a se desmanchar/liquefazer no ciberespaço.

Contraditoriamente frágil e duradoura, a permanência do objeto carta e os atos de enviar, conservar, destruir - incluindo pedidos para rasgar e queimar as mais

4 A origem da mensagem epistolar é limítrofe com a própria criação da escrita, situada por volta de 3.000 anos a.C, com seus primeiros registros nas civilizações da Mesopotâmia (cf. BOUVET, 2006, p. 3I-40). 
comprometedoras -, seguidos de recuperações miraculosas, ganham contornos romanescos, nos quais o acaso colabora para a propagação da mensagem para além do destinatário previsto. Assim, “Toda carta es un albur”s (BOUVET, 2007, p. 7I), e a sobrevivência do objeto incita a um novo pacto de leitura, agora, com um leitor alheio à relação epistolar inicial.

Também a distância temporal da produção/envio pelo correio transforma, aos olhos da posteridade, o que havia de circunstancial e transitório no texto, dando novos contornos aos acontecimentos particulares de uma existência. Remetente e destinatário são inscritos na mensagem, premidos entre a convenção e a invenção das tópicas epistolares, reunindo, portanto, as dimensões íntimas e coletivas no texto. No meio acadêmico, é consenso pensar que a correspondência de um autor recebe o status de documento e realiza o registro cotidiano de hábitos culturais e de formas de pensamento, incorporando, na sua textualidade, os modos de viver e as modas retóricas/estilísticas da época vivida por ele.

No caso de missivistas célebres, a correspondência subsidiará, junto com outros escritos íntimos, as biografias dessas personalidades. Por outro lado, quando se trata das cartas de artistas, os textos são laboratórios onde se acompanham os projetos, a gênese e a discussão das obras. Assim, na condição de work in progress, as cartas erguem-se, como um paratexto, um espaço de criação, conforme nos recorda Marcos Antonio de Moraes (2008, p. 8): "A correspondência de artistas e escritores poderá igualmente afirmar-se como um agitado "canteiro de obras". Intimamente presa a um autor e sua história, a carta torna-se um "reservatório da ficção", assumindo qualidades de "obra poética" em que "é difícil separar do horizonte afetivo as qualidades do estilo" (HAROCHE-BOUZINAC, 20I6, p. I79).

Para outros, uma carta pode ser o espelho de uma alma, um autorretrato que se equilibra na difícil tarefa entre a "subordinação do ego" (HAROCHE-BOUZINAC, 20I6, p. I47) e a presença do destinatário. O caráter confessional estimula a encenação de si, que, por vezes, transgride os limites considerados de bom-tom para o desabafo e deixa o interlocutor num segundo plano, levado, de roldão, pelas paixões egotistas do remetente.

Nesse caso, a carta "é uma cena" (HAROCHE-BOUZINAC, 20I6, p. I37) e apresenta aspectos dramáticos, não apenas na emulação da oralidade e do diálogo, mas também na ilusão representativa que envolve tanto o remetente, quanto o destinatário. Não sendo possível conhecer as intenções subjetivas, ou mesmo mensurar o grau de verdade e mentira dos sentimentos expostos, reconhece-se, entretanto, que a armadilha da sinceridade e simplicidade do gênero não oculta, por completo, um poderoso arsenal retórico. As táticas de convencimento e persuasão convertem, por vezes, o gesto epistolar em uma "atividade sacrificial" (HAROCHE-BOUZINAC, 20I6, p. I08), até mesmo aumentando a dor e o sofrimento dos interlocutores, ao reafirmar a ausência, a perda e a impossibilidade de comunicação.

O admirável mundo novo das representações de si, propagando perfis heteronímicos e virtuais, talvez seja uma nova etapa da mise-en-scène do espaço epistolar, em que o remetente se mira no destinatário, forjando, mimeticamente, o

5 Toda carta é um acaso (tradução nossa). 
estilo, os assuntos e expressão de sentimentos. Por fim, na condição de testemunho de extremos, é o "último recurso [...] companheira inseparável do encarceramento e da dissidência” (HAROCHE-BOUZINAC, 20I6, p. 2I4).

Nostálgicos da materialidade perdida, mas também admiradores da "eficácia afetiva” (HAROCHE-BOUZINAC, 20I6, p. 2I3) incomparável e insubstituível da carta, depreende-se, nos múltiplos conceitos e descrições do gênero, as qualidades que alimentaram a urgência para seu resgate e conservação, bem como o sucesso editorial dos epistolários de artistas e escritores em geral. Contudo, para além das características intrínsecas e inigualáveis da carta, o que moveria o leitor, que está fora do pacto epistolar, para esses textos lacunares e evasivos? Refletindo sobre a correspondência de escritores, que contém as cartas de maior sucesso de público, o que o leitor busca para além dos fatos biográficos e do registro genético das obras de arte?

Se a figura do autor torna-se, aparentemente, mais acessível através dos veículos midiáticos e das interações nas redes sociais, segue a curiosidade do público e, por que não admitir, do crítico, em conhecer aspectos confidenciais, cuidadosamente, guardados e dirigidos à confiança do destinatário. Assim, a carta possui a atração de um baú de histórias, pronto a ser revirado na tentativa de conhecer aspectos inusitados da vida e da obra do artista, conforme observa Walnice Nogueira Galvão (2008, p. 20): "Noto uma mentalidade de voyeur no leitor de cartas, tanto quanto no estudioso de literatura, no crítico literário. A gente quer o segredinho, o diário íntimo, a carta, o trecho cortado, a gente quer o rascunho das obras, a gente quer tudo...”.

Conforme demonstra Haroche-Bouzinac (20I6, p. I4-I6), dentre as três leituras possíveis para a carta, dizem respeito ao leitor póstero as que se dão no espaço exterior da dupla epistolar e a de natureza meditativa. Deambular pelas zonas de sombra de uma expressão pessoal, de uma mensagem marcada pela opacidade e pela obliquidade, cuja motivação inicial já se perdeu no "enxurro da vida", seria uma das leituras possíveis ao leitor do gênero. $\mathrm{O}$ olhar de quem percorre uma correspondência se torna fundamental na atribuição de sentido para a mensagem e, à moda de um romance, decifram-se os rastros dessas vidas, transformando remetente e destinatário em personagens, e "o desejo de viver outras vidas por procuração pode estar na origem da descoberta, da esperança de encontrar receitas de vida" (HAROCHE-BOUZINAC, 20I6, p. I6).

Para além do prazer do texto, que compartilha, como vimos, qualidades estéticas, dramáticas e poéticas que o aproximam da literatura, esse desejo último não é de somenos importância e, arriscamos afirmar, impulsiona, extraordinariamente, a motivação de leitura. Advertindo sobre o risco dum novo "equívoco" para os incautos que buscam "extrair desses testemunhos um saber antropológico sobre os comportamentos humanos, modelizando atitudes de vida" (HAROCHE-BOUZINAC, 20I6, p. I6), a crítica francesa considera até mesmo ingênuo um dos principais argumentos usados na apresentação editorial desses textos para os leitores. Relativiza-se, desse modo, o mito da transparência, que tornaria "a carta depositária da verdade do indivíduo" (HAROCHE-BOUZINAC, 20I6, p. I6).

Avisos à parte, mesmo com a ressalva da presciência dum leitor póstero ou da carga dramática e retórica do gênero, a correspondência de escritores segue exercendo fascínio, adquire importante relevância e "tanto pode ser 'material 
auxiliar', ajudando a compreender melhor a obra e a vida literária, quanto escrita que valoriza a função estética/poética” (MORAES, 2008, p. 9). Por seu caráter fronteiriço, proteiforme e dinâmico, a carta se movimenta em zonas difusas em que biografia, história e ficção se entremeiam, conforme nos recorda Todorov (20I4, p. 20):

A carta se situa a meio caminho entre o puramente íntimo e o público, dirigindose então a outra pessoa para quem aquele que escreve se caracteriza e analisa, mas esse outrem é um indivíduo conhecido, não uma massa impessoal. As cartas sempre manifestam uma faceta do autor - sem ser, por isso mesmo, uma janela transparente que se abre sobre sua identidade.

Em seu estudo sobre Oscar Wilde, Rainer Maria Rilke e Marina Tsvetaeva, Todorov elege, dentre os escritos íntimos, a carta como principal gênero, possibilitando vislumbrar o ideal de arte vivido, às vezes, de forma funesta por esses poetas. Nesses textos, o jogo das dimensões íntimas e coletivas alcança uma complexidade peculiar e, tal uma fita de Möbius, não se consegue separar vida e arte. As cartas de escritores tornam-se, portanto, a realização mais plena do "viver-escrever" ou "escrever - é viver" (TODOROV, 20I4, p. 248). Nem puramente biográfica, nem totalmente literária, a carta está na encruzilhada desses caminhos paralelos e de difícil escolha para os missivistas.

Todorov, igualmente, passa pelo questionamento do propósito de leitura das cartas de escritores e destaca o demasiado humano expresso nas/pelas linhas epistolares. Retomando a tópica clássica em que a narração das situações individuais subsidia reflexões sobre a vida em geral, o crítico destaca o caráter exemplar dessas trajetórias existenciais e, em movimento reverso, persegue a estreita relação com os ideais estéticos e filosóficos em que estavam imersos. A carta, assim como a literatura, permite que seus correspondentes ultrapassem as contingências humanas: "o poeta não conhece a morte. Ou ainda: a morte não o impede de continuar a doar, simplesmente ele não pode mais receber" (TODOROV, 20I4, p. 248). Nesse sentido, a carta é uma lição a ser transmitida: "Mas essas vidas, com seus projetos, voos e reveses, se tornaram elas mesmas partes do mundo carregadas de sentido. Nós, cujas existências não são ainda terminadas nem, portanto, determinadas, temos algo a aprender com essas vidas" (TODOROV, 20I4, p. 252).

Expressão da "descontinuidade própria à espécie humana" (TODOROV, 20I4, p. 255), a busca pela plenitude entre vida e arte encontra na carta um lócus privilegiado. Dentro da clave de leitura proposta por Todorov sobre uma tradição dualista que opõe "uma existência finita e [...] um consciência aberta ao infinito" (TODOROV, 20I4, p. 255), faremos a leitura da lição deixada por Mário de Andrade, poeta e notável missivista. Carlos Drummond de Andrade (I988, p. I2) já havia percebido o sentido exemplar e a importância da divulgação e leitura das cartas marioandradinas por sua "poderosa magia verbal, pela espontaneidade, pelo insólito e pela riqueza dos pontos de vista que defendeu, como professor de nova espécie, num permanente ensinar, cortado de dores físicas, de dificuldades financeiras e de muito e desprendido amor".

Autorretrato de uma personalidade inquieta e criativa, mas também testemunho das mudanças e embates vividos pelos artistas brasileiros no início 
do século XX, a correspondência do escritor modernista está num dos principais enclaves da disputa entre as "formas de absoluto", como identifica Todorov. Entre I9I5 e I945, as radicalizações entre arte e política lançam sociedades inteiras num turbilhão revolucionário:

Após a Primeira Guerra Mundial, as vanguardas artísticas, seja na Rússia, na Alemanha ou na Itália, querem estender o campo de suas ações criadoras até que cubram toda a vida; seus representantes se fazem propagandistas, fabricantes de uma arte do real, arquitetos. Por outro lado, os ditadores que tomam o poder nesses mesmos três países adotam, com menor ou maior consciência, a atitude do artista que modela com toda liberdade um homem novo, uma nova sociedade, um novo povo. Artistas de vanguarda e chefes totalitários compartilham, na maior parte do tempo sem o saber, um mesmo projeto revolucionário. (TODOROV, 20I4, p. 309).

Mário de Andrade, como tantos outros vanguardistas das primeiras décadas do século XX, precisou encontrar respostas para os dilemas entre a arte e o engajamento político. A correspondência abrange desde o entusiasmo da década de I920, quando se faz promotor do Modernismo, arregimentando outros para o projeto para a cura da "moléstia de Nabuco"6 e a tentativa de dar "alma" ao Brasil, até a postura artística mais sóbria das décadas de I930-I940, cujo clima bélico torna obsoleta a blague modernista e arrefece o otimismo em relação ao país.

O relato pungente e vibrante de quem optou "estraçalhar" a própria obra na participação ativa da cena cultural brasileira também nos legou reflexões sobre o indivíduo num cenário de radicais polarizações, especialmente aos jovens que se aventuram nas sendas artísticas e buscam seu lugar no mundo, conforme indica Carlos Drummond de Andrade (I988, p. IO): "encontrarão por certo resposta a umas tantas inquietações comuns a cada geração, como inerentes à mocidade, quaisquer que sejam os problemas e a face do mundo que lhes correspondam". Buscamos, assim, no intervalo entre "projeto de vida e verdade de existência" (TODOROV, 20I4, p. 24), refletir sobre o relato epistolar marioandradino, as lições depreendidas de seu esforço na conciliação entre vida e arte, ou da proposta de uma arte de viver, escolhendo para o diálogo Murilo Miranda, moço de pequena bagagem intelectual que, nos quinze anos de existência da Revista Acadêmica, não se limitou ao trabalho de editor e comunicador cultural, ao contrário, foi poeta "em estado de graça"7, com presença na Antologia dos poetas brasileiros bissextos contemporâneos (I946), organizada por Manuel Bandeira, na qual figura um poema dedicado ao autor da coletânea:

6 A expressão aparece na segunda carta destinada a Carlos Drummond de Andrade, aproximadamente de I924, em que critica a postura do intelectual brasileiro que suspira pela Europa, discutindo a necessidade de ser nacional para alcançar o universal. Nela faz o convite ao jovem Carlos para participar do "trabalho de abrasileiramento do Brasil” (cf. ANDRADE, I988, p. 30).

7 Na expressão de Manuel Bandeira, "Bissexto é todo poeta que só entra em estado de graça de raro em raro" (BANDEIRA, I996, apud MIRANDA, 2020). 


\title{
Poema para Manuel Bandeira
}

\author{
Tudo quanto existe em ti \\ De mais propenso ao silêncio, \\ A solidão insondável, \\ Chora e ri com o mesmo gozo, \\ Os mesmos risos e lágrimas.
}

\author{
Na grave voz que soluça, \\ No desengano de tudo, \\ Tua ironia é volúpia: \\ - Uma volúpia esquisita; \\ Feita de tudo e de nada. \\ (Murilo Miranda apud MIRANDA, 2020, s.p.).
}

À revelia de Mário de Andrade, que o aconselhou a não ter ilusões com edições de luxo no Brasil porque ele corria o risco de "esmolar de porta em porta [...], guardar na paciência olhares de desconfiança, engolir recusas, e o diabo [...]" (ANDRADE, I98I, p. I47-I48), Murilo resolveu editar o Mangue, álbum com 42 dos desenhos feitos por Lasar Segall para a exposição do Museu Nacional de Belas Artes do Rio de Janeiro em I943.

A mostra causou polêmica e gerou discordâncias entre os que eram contrários ao engajamento do artista em questões político-sociais. Indiferente às críticas, Murilo convidou Mário de Andrade, Manuel Bandeira e Jorge de Lima para escreverem o prefácio da obra. Os textos de Bandeira e Lima enaltecem o talento do artista e defendem o valor humanista e poético do trabalho de Segall, ao passo que Mário conjura o seu inconformismo na carta de I6 de abril de I943, na qual não esconde que está mais interessado na quantia a receber do que na reflexão sobre os desenhos, alegando as circunstâncias pouco edificantes: "A proposta de prefácio crítico para o álbum de desenhos de Segall é quase uma... chantagem. Tudo quanto seja proposta pra ganhar dinheiro, agora é chantagem, aceito" (ANDRADE, I98I, p. I4I). Em seguida, se apressa em ilustrar a versatilidade de seu gênio criador: "Posso fazer um prefácio assim meio espiritualmente granfino, ou melhor refinado, um bocado à maneira de Valéry, o quanto o meu temperamento der com isso" (ANDRADE, I98I, p. I4I).

Nas palavras de Fábio Magalhães em "Poéticas do Mangue”, Mário não se preocupou com o Mangue, limitando-se a desenvolver "uma reflexão sobre o desenho sem se deter, até mesmo, na análise da obra de Segall”.

De qualquer forma, insinuando-se nas cartas de Mário, Murilo dava sinais de resistência, que atiçavam o entusiasmo do epistológrafo a continuar no exercício do pensamento compartilhado, confiando que seu "Irmão Pequeno, pequenino e infantil” (ANDRADE, I98I, p. I40) esforçava-se por pressentir e compreender o amigo extraordinário, que encontrara àquela altura da vida. Sem dúvida, deu-se o mesmo com o intelectual do Rio. 


\section{Caminhos que se possam dar?}

O que será de mim, ainda não sei bem, sei que a vida mudou. Não faço projetos, deixei os que tinha comigo pra mais tarde (ou quem sabe nunca?...), estou cheio, trabalhando com paixão, com violenta paixão, nesta primeira vida minha em que tomo contacto burocrático com o povo e com a vida. (ANDRADE, I98I, p. I8).

Na convicção de que a carta é um documento assinado e selado diante de testemunhas, Mário de Andrade é um missivista que seleciona seu destinatário e, entre os correspondentes, que participaram de sua inteligência e jogo de espírito, um lugar nada desprezível cabe a Murilo Miranda, advogado e escritor de grande bagagem cultural. De I934 a I945, as cartas enviadas para o editor são narrativa densa e enérgica, meio profissional e meio confidencial, nas quais o escritor, aspirando a uma forma prática de ação política, tinha aceitado o cargo de diretor no Conservatório Dramático e Musical de São Paulo, onde estudou e trabalhava como professor. Ao mesmo tempo, profundamente lírico e dramático, inquietava-se e sofria por não ter sequer um momento de tranquila satisfação para prosseguir com seus projetos literários. De I934 a I937, foi arrastado pela engrenagem de atividades desgastantes, redigindo documentos e assinando processos, levado pelo ideal de assegurar arte e cultura acessíveis a todos, criando bibliotecas itinerantes, promovendo cursos populares de formação literária, patrocinando espetáculos de música e teatro.

$\mathrm{Na}$ vivência das experiências novas, carta e diário integram-se no diálogo com Murilo Miranda para dar conta da realidade de um sujeito que se movia mal entre a abjeção à estatizante burocracia oficial e a dolorosa luta para prosseguir na construção identitária de fazer "arte de ação". O eu, que dá voz à longa narrativa de I5 de maio de I935, escreve sobre pressão, está melancólico e excessivamente cansado, como se suas aspirações tivessem sido solapadas por causas reacionárias, que excluíram do seu programa a liberação dos seus sonhos de artista. A linguagem busca aproximação, consolo e solidariedade:

Murilo,

Estou lhe escrevendo no intervalo das horas, não tenho tempo [...]. E não comento nada, estou sem vontade e sem poder. [...] Sinto saudades mesmo, mas sinceramente, uma saudade meio melancólica, de quem carece como que duma espécie de apoio, ou de paciência dos outros. Como é difícil subir na vida pros indivíduos que nem eu, especialistas da paz do seu próprio quarto. Se você quiser me compreender com amizade, posso lhe confessar que... tenho medo. É bem mesmo uma espécie de medo, e não de esperança ou desejo, que me fez ficar assim como estou, estes tempos, completamente ausente de mim. Até breve [...]. (ANDRADE, I98I, p. I4-I5).

Para o servidor público, a correspondência tornava-se a alternativa crítica para se colocar em oposição a esse outro que precisava extravasar a sua contrariedade contra o ofício que fazia com que "o da literatura" não tivesse o prazer de reviver uma lembrança espontânea e ter alegrias. É essa a disposição 
fixada na carta de 2 de agosto de I935, escrita depois de um dia dedicado ao departamento: "ah que saudades do tempo em que a cada princípio de carta me botava pensando: Mas que dia é mesmo hoje?... Nunca eu sabia a quantas andava da exigência do mundo. Agora?” (ANDRADE, I98I, p. 2I). Com ironia e sarcasmo, avisava que era realmente um, "oh oh Diretor do Departamento de Cultura e Recreação da Municipalidade de S. Paulo, vulgo Cidade Anchietana", com "um milhão" (ANDRADE, I98I, p. 22) de encontros e entrevistas agendadas. Mergulhado na situação, o remetente misturava informações sobre o cotidiano agitado, com desejos e pensamentos: "Vou ver se em junho vou aí, depende da Rádio-Escola, o maior tropeço, a caquira do Departamento, cruz credo!, não há meio de resolver" (ANDRADE, I98I, p. 33).

Todavia, era sob a forma de conversação afetuosa que vinham as confissões que traduziam o quanto Mário se aproveitava da carta para dar notícias e trocar informações, mas sobretudo para revelar o quão importante era, para ele, a presença de Murilo, e que a amizade pura, mesmo à distância, propiciava prazer e bem-estar àquele que naturalmente se entregasse à sua prática:

Há um segredinho no mundo - que se chama querer bem... etc. [...]. A gente vai, começa com literatura, começa falando em revista, e de repente se percebe que está ultrapassado o período literatura o período revista do convívio, e a contiguidade dos seres criou uma coisa mais profunda. Foi o que sucedeu conosco, e talvez nem nós puséssemos reparo nisso, sucedeu. Eu quero bem você, e pronto. (ANDRADE, I98I, p. 2I-22).

No entanto, a estreita relação entre o senhor e o moço da revista não evoluiu de forma tão harmoniosa como se poderia esperar de uma correspondência na qual um se expõe abertamente, enquanto o outro, com pouco mais de 20 anos, orbitava ainda às margens do espaço profissional e literário. Junto com Lúcio Rangel, Moacir Werneck de Castro e Carlos Lacerda, amigos da Faculdade de Direito, Murilo compartilhava o gosto pela literatura e era afetado pela belicosidade ideológica de sua geração. Naquele momento, o grupo decidiu fundar a Acadêmica, uma revista inspiradora, capaz de oferecer resistência às ideologias conservadoras e avançar além da polarização política e divisões literárias, que imperavam no meio intelectual da época. Tendo Murilo Miranda como interlocutor, as declarações, explicações e debates engendrados por Mário têm como cenário a história desse tempo, o que transforma a carta não só em conversação entre amigos mas também em testemunho e reflexão a partir de um signatário às voltas com um cargo que ambicionava e que aceitou após muitas hesitações.

No artigo "Suas cartas, nossas cartas", Silviano Santiago (2006, p. 89) acentua que, diferente de Carlos Drummond de Andrade, que, desde a primeira carta em I924, procurava o reconhecimento do intelectual paulista, "a nova geração exige, cobra, coteja, coloca contra a parede os velhos", e acrescenta com propriedade:

Mário historia - com cuidado pouco comum em intelectuais brasileiros - o percurso da sua vida de artista/servidor público. Em primeiro lugar, define o emprego público como "suicídio" passageiro do artista. (“O Departamento é meu túmulo. Não sei quanto 
tempo durará esse túmulo.”). Em seguida, considera que a atividade do artista, na qualidade de servidor público, não deve traduzir ação político-partidária, mas antes deve recobrir-se pelos princípios da "arte de ação pela arte”. (“O Departamento vinha me tirar do impasse asfixiante, ao mesmo tempo em que dava ao escritor suicidado uma continuidade objetiva à sua ‘arte de ação' pela arte.”) ${ }^{8}$.

O primeiro encontro entre Mário e Murilo aconteceu em São Paulo, quando Lúcio Rangel e ele foram a São Paulo pedir ao escritor um livro para dar início às atividades da Acadêmica. Na carta-resposta, antes de enviar o original solicitado, de 28 de novembro de I934, o signatário adentra no território do pedinte com precaução, alegando "certa questão de idade”. Prevendo a imprevisibilidade financeira da dupla, afirmava sem rodeios: "Uma coisa é querer e outra muito diferente é poder querer [...]. Minhas condições vocês já conhecem e repito, de maneira que esta carta possa servir de garantia pra vocês” (ANDRADE, I98I, p. II).

Não faltou também a advertência de que a iniciativa dos moços da revista acarretaria despesas extras ao apostarem num produto pouco vendável: "Mas não façam edição muito grande que perderão. [...]. No Brasil meus livros se vendem pouco” (ANDRADE, I98I, p. II-I2). Passo a passo, o "mais experiente" se apresentava como um homem maduro, "feito de outros provérbios", que tinha uma trajetória de vida a preservar. Dessa feita, de acordo com o combinado, o grupo editou dois ensaios enviados pelo autor: "O Aleijadinho e sua posição nacional” e “Amor e medo”, sobre Álvares de Azevedo, que foram publicados de acordo com as exigências do autor.

Na sequência dos assuntos, a partir da segunda carta, de I de fevereiro de I935, já é o Mário no seu lento processo de "suicídio" que se presentifica diante do "irmão mais novo", deixando transparecer o seu abatimento físico e moral: "são 24 horas e vou lhe escrever estas linhinhas à pressa quase que mais pra me desabater. É que tive hoje uma luta grande dentro de mim entre não-sei-o-quê e a felicidade” (ANDRADE, I98I, p. I3).

O discurso ampliou-se até a concepção de que "o não-sei-o-quê" encontrava sua causa na "violenta paixão" com que se lançou no trabalho. Ele que sempre foi um apaixonado "pela vida mesmo em todas as suas formas de viver", aceitou a nomeação na crença de que seria a porta aberta para a realização efetiva dos seus projetos sociais de desenvolvimento e expansão da arte e da cultura nacional, porém, por trás da trabalheira de funcionário dependente da morosidade estatal, escondia-se a rivalidade dos opositores, a conveniência dos bajuladores, a falta da leitura e da escrita. A linguagem, fortemente adjetivada de 27 de maio de I935, expressava "o horrível vazio [e] a sofredora hesitação mental” (ANDRADE, I98I, p. I8), que degradava o intelectual forçado à banalidade do cotidiano.

Nesse contexto, a carta age e tem a função de quebrar a monotonia dos dias. Mário não se cansava das cartas, e receber notícia do "irmão mais novo" era o estímulo que o fazia vibrar de entusiasmo: "A terceira carta é a sua, e me apertou uma saudade tão doída de conversar com você, ficar assim a gente 'em dois' [...], se contando nada, simplesmente pelo prazerzinho de estar em dois e em amizade” (ANDRADE, I98I, p. I7). No entanto,

8 Os fragmentos citados nos parênteses encontram-se na longa carta de II de novembro de I936 (cf.: ANDRADE, I98I, p. 34-42). 
o jeito de ser e de agir de Murilo gerava controvérsias, inversamente proporcionais, ao discurso das gentilezas e troca de amabilidades.

A leitura atenta da carta de 9 de maio de I936, na qual Mário nega o pedido de emprego feito pelos rapazes do Rio - "São I7 horas e três minutos e respondo imediatamente. E a resposta é não" (ANDRADE, I98I, p. 28) -, nasce de uma contrariedade e pode ser analisada como o testemunho ético e consciente de um modo de ser quando se está à frente de órgão público. Rejeitando os floreios literários, Mário inicia a sua preleção contra os pedidos de emprego, afirmando: "não há vergonha nenhuma em lutar por emprego tendo habilitação pra ele", contudo, os rapazes da Acadêmica, Murilo e Lúcio abusaram, foram fúteis e superficiais, eles o "usaram apenas, e no mais perfeito, no mais profundo sentido da amizade” (ANDRADE, I98I, p. 28).

Em seguida, entra diretamente no debate ao empreender uma discussão acalorada contra as cooptações, as estratégias dúbias de promoção e os "jeitinhos” que colocavam desonestidade e malandragem em toda parte. Segue nesse tom, lembrando que preferiu padecer a aceitar que o seu grande amigo, Manuel Bandeira, próximo de Gustavo Capanema, o ministro da Educação de Getúlio Vargas, intercedesse pela sua nomeação. Na evolução, incumbe-se de contar o episódio familiar, que ocorreu com o seu pai e que marcou sua experiência a ponto de convertê-lo num homem avesso a qualquer pedido, mesmo que fosse para facilitar o seu acesso a posições de qualquer ordem. Quase todos os dias, à mesa do jantar, seu pai repetia alto para que os filhos ouvissem: "Vocês nunca me peçam nada pra ninguém. Morram mas não me peçam etc." (ANDRADE, I98I, p. 3I). A densidade desse discurso ecoava no seu íntimo e o "marcou com ferro, com um ferimento ardente que jamais conseguiu acabar" (ANDRADE, I98I, p. 3I). Por fim, ferido em sua dignidade, fecha a questão sem dar margem à réplica: "Desta vez vocês erraram muito e estragaram com o resto do dia. Não venham pedindo desculpa, é besteira: eu sei compreender" (ANDRADE, I98I, p. 32).

O momento político no Brasil e no exterior também rendeu passagens escriturais dignas de registro, motivadas pela tendência ideológica e literária do grupo. Segundo Moacir Werneck de Castro (I989, p. 72), Murilo Miranda não era um esquerdista radical, "comprava literatura marxista em traduções francesas, mas a consumia com moderação". Por sua vez, apesar de alardear o seu propalado "antipolitiquismo essencial”, Mário não admitia inteiramente o marxismo, embora Karl Marx, Nikolai Bukharin e Georges Friedmann fizessem parte de suas leituras. Entretanto, quando Murilo o convidou para colaborar no número da revista dedicado ao "comunista" Romain Rolland', prêmio Nobel de Literatura de I9I5, ele recusou com a desculpa de que "estava enervado, fatigado de literatices e sociologices [...], porque queria bestar, ver o Pão de Açúcar sem Romain Rolland, sem Revista Acadêmica, sem pintura nem nada" (ANDRADE, I98I, p. 29).

Mesmo filiado ao Partido Democrático, era sabido que Mário repudiava o engajamento partidário por considerá-lo prejudicial ao trabalho do artista, movimentava-se esteticamente em espaço dissidente, procurando escutar a própria voz a obedecer às regras do jogo político. Sob essas condições, em 9 de junho de I942, Mário

9 No capítulo "Marxismo romântico", Moacir Werneck de Castro (I989, p. 75-77) chama a atenção do leitor para a atitude ingênua de Mário em relação ao escritor francês, que defendia as grandes causas da paz e da liberdade de ação e pensamento no mundo. 
reagiu à cobrança de Murilo, que não queria que ele publicasse o ensaio sobre Tristão de Athayde, pseudônimo de Alceu Amoroso Lima, crítico literário e líder católico com ideias conservadoras. Mais uma vez, Mário discute o seu ponto de vista e fustiga a futilidade e a perversão de uma amizade, que se submete cegamente às vaidades dos elogios com vocábulos grosseiros, mas certeiros quanto à mensagem:

Si eu sacrificasse um naco daquilo que é a dignidade e o sofrimento do meu espírito só pra agradar esta nossa amizade, vocês seriam os primeiros a me desprezar. Gostavam porque isso ajudava mais o ideal de vocês, mas eu não passaria pra vocês de um papel de servir, um papel higiênico, porra! [...]

Não posso, Murilo, não posso. Esse sacrifício da minha verdade eu não posso fazer. (ANDRADE, I98I, p. II4).

Sem se aprofundar no debate que se instaura nessa carta e no decorrer das seguintes, pode-se recensear que novas dicotomias foram geradas entre o jovem, que fingia ignorar que lidava com um "homem de 48 anos feitos", que não escondia sua formação e seus princípios (cf. ANDRADE, I98I, p. II6). A relação epistolar entre os dois segue nesse tom, com o missivista impondo a sua gramática e o seu vocabulário singular. No entanto, embora vivesse na clivagem entre o social e o individual, o público e o privado, nota-se que Mário, na relação epistolar com Murilo Miranda, procura refugiar-se das turbulências do mundo conflagrado à sua volta, demarcando a carta como o território protegido do íntimo, lugar de "onde uma palavra verdadeira pode enfim advir" (DIAZ, 20I6, p. 36).

Nas páginas endereçadas a Murilo Miranda, o homem "adoentado, fatigado, fatigadíssimo" (ANDRADE, I98I, p. 48) sente-se na sua obsessão de uma subjetividade falante e comunicativa, que se expressa graças ao desvio em direção ao outro, o interlocutor escolhido: "Talvez seja exatamente pela diferença de idade que melhor nós nos podemos replantar um ao outro em nossas ilusões e esperanças dizimadas" (ANDRADE, I98I, p. 52). A rica adjetivação forjada pelo escritor reveste Murilo com a aura dos escolhidos: era o "irmão pequeno", o "irmãozinho" e, "com todos os seus defeitos, uma das almas mais lindas, mais puras, mais generosas, mais dignas de admiração" (ANDRADE, I98I, p. 52) que encontrou na vida.

Acontece que, nas Cartas a Murilo Miranda, Mário de Andrade mistura o olhar sobre si mesmo, sobre o destinatário e a história do seu tempo, ao mesmo tempo que tece uma narrativa fragmentada, densa e humana. Atrás do seu sofrimento, vivia um introspectivo solitário, altruísta o bastante para vencer a inércia e voar titubeante em direção aos outros...

\section{Considerações finais}

No artigo "70 anos de morte de Mário de Andrade”, publicado no Estado de S. Paulo, em 2I de fevereiro de 20I5, Silviano Santiago ponderava sobre a importância da atuação de Mário de Andrade no campo da arte e da cultura brasileiras e afirmava que ele poderia ser considerado o maior intelectual brasileiro do século XX. De fato, de I922 até a sua morte em I945, "o homem multiplicado por mil" (TODOROV, 20I4, p. I87) foi incansável na realização do projeto de modernização do país e, através de seus 
textos, deixou testemunhos eloquentes de sua experiência literária e profissional, indo tão longe quanto possível na defesa intransigente de fazer "arte de ação pela arte", e jamais arte pura e desinteressada.

Foi assim que se tornou funcionário público e passou a viver "sem felicidade quase nenhuma, um corpão monótono e de enorme malinconia” (ANDRADE, I98I, p. 48), sem tempo para ler nem escrever, hábitos prazerosamente cultivados por quem tinha o poder notável "de gostar mesmo da vida e de tudo o que está dentro dela" (ANDRADE, I98I, p. 67).

Portanto, as cartas para Murilo Miranda engajam aquele que as escreveu não só à literatura, como também à história de um Brasil dividido politicamente sob o regime ditatorial do Estado Novo, sofrendo ainda com as consequências da Segunda Guerra Mundial na Europa. Dessa forma, se a escrita epistolar foi para Mário de Andrade um meio de criação e de subjetivação, com lugar e funções variáveis, essa correspondência transgride os limites convencionais do gênero e, pelo seu valor literário e histórico, anseia por maior aprofundamento, clamando inclusive pela voz do interlocutor a quem se destina...

\section{SOBRE AS AUTORAS}

MÔNICA GOMES DA SILVA é professora adjunta da Universidade Federal do Recôncavo da Bahia (UFRB). mgs@ufrb.edu.br https://orcid.org/o0o0-0002-9610-3017

MATILDES DEMÉTRIO DOS SANTOS é professora da Universidade Federal Fluminense (UFF). mdemetri@terra.com.br https://orcid.org/oooo-0002-9607-6549

\section{REFERÊNCIAS}

ANDRADE, Carlos Drummond de. Apresentação. In: ANDRADE, Carlos Drummond de. A lição do amigo. 2. ed. Rio de Janeiro: Record, I988, p. 9-I2.

ANDRADE, Mário de. Mário de Andrade: cartas a Murilo Miranda (I934-I945). Org. Yedda Braga Miranda. Rio de Janeiro: Nova Fronteira, I98I.

BOUVET, Nora Esperanza. La escritura epistolar. I. ed. Buenos Aires: Eudeba, 2006. (Enciclopedia Semiológica).

CASTRO, Moacir Werneck de. Mário de Andrade: exílio no Rio. Rio de Janeiro: Rocco, I989.

DIAZ, Brigitte. O gênero epistolar ou o pensamento nômade. Trad. Brigitte Hervot e Sandra Ferreira. São Paulo: Edusp, 2016. 
GALVÃO, Walnice Nogueira. À margem da carta. Entrevista realizada por Marcos Antonio de Moraes. Teresa revista de Literatura Brasileira [8I9]; São Paulo: Ed. 34, Universidade de São Paulo, n. 8/9, 2008, p. I4-29.

HAROCHE-BOUZINAC, Geneviève. Escritas epistolares. Trad. Ligia Fonseca Ferreira. São Paulo: Edusp, 2016. MAGALHÃES, Fábio. Poéticas do Mangue. Disponível em: museusegall.org.br/pdfs/texto_Fabio_Magalhaes_PT.pdf. Acesso em: 26 ago. 202I.

MIRANDA, Antonio. Murilo Miranda. Disponível em: http://www.antoniomiranda.com.br/poesia_brasis/ rio_de_janeiro/murilo_miranda.html. Acesso em: 26 ago. 202I.

MORAES, Marco Antônio de. Sobrescrito. Teresa revista de Literatura Brasileira [8I9]; São Paulo: Ed. 34, Universidade de São Paulo, n. 8/9, 2008, p. 8-9.

MURILO MIRANDA é quem escreveu mais. Folha de S. Paulo, Ilustrada, 22 de julho de I997. Disponível em: http://wwwr.folha.uol.com.br/fsp/ilustrad/fq220725.htm. Acesso em: I2 jun. 2017.

SANTIAGO, Silviano. Suas cartas, nossas cartas. In: SANTIAGO, Silviano. Ora (direis) puxar conversa!: ensaios literários. Belo Horizonte: Editora UFMG, 2006, p. 59-96.

SANTIAGO, Silviano. 70 anos de morte de Mário de Andrade. O Estado de S. Paulo, 2I de fevereiro de 2015. Disponível em: https://cultura.estadao.com.br/noticias/literatura,nos-70-anos-de-morte-de-mariode-andrade-ainda-e-tempo-de-estudar-sua-obra,I637275. Acesso em: 26 ago. 202I.

SANTOS, Matildes Demetrio dos. Carta aos moços. In: SANTOS, Matildes Demetrio dos. Ao sol carta é farol: a correspondência de Mário de Andrade e outros missivistas. Rio de Janeiro: Annablume, I998, p. 2IO-23O.

TODOROV, Tzvetan. A beleza salvará o mundo: Wilde, Rilke e Tsvetaeva - os aventureiros do absoluto. 2. ed. Rio de Janeiro: Difel, 20I4. 